\title{
Effectiveness of Physical Activity Program in Improving the Self-esteem of Female Elderly in Rural Areas
}

\author{
Soo-Yeon Goh ${ }^{1}$, Eun Kyung Yoon ${ }^{2}$, Mi-Na Lee ${ }^{3}$ \\ ${ }^{1}$ The Doctor's Course, Department of Human Service Education, Kwangshin University, South \\ Korea,gogo1000@hanmail.net \\ ${ }^{2}$ Adjunct Professor, Department of Human Service Education, Kwangshin University, South Korea, \\ lastage@hanmail.net \\ ${ }^{3}$ Professor, Welfare Counseling Convergence Department, Kwangshin University, South Korea, \\ lmn4780@naver.com
}

Corresponding author: $\mathrm{Mi}-\mathrm{Na}$ Lee

\begin{abstract}
This study is aimed to investigate the effectiveness of self-esteem-enhancing physical activity programs for women in rural areas. The subjects are 20 women aged 80 or older at the B Senior Welfare Center located in Jeonlanam-do (ten experimental groups and ten control groups). The study was conducted ten times from 3 March 2021 to 26 May 2021. The self-esteem research tool was used to gather data. The data collected was analyzed using the IBM SPSS Statistic 20.0 program. Preexamination of experimental and control groups was conducted with independent sample t-validation, and covariate analysis (ANOVA) with pre-score covariate was performed to identify the difference in mean between groups. Based on the results of the study; first, the physical activity program of the elderly in rural areas reflected the situations and desires of the participants and applied the program after consultation with experts. Second, the physical activity program of the elderly in rural areas is effective in "value, pride, ability, respect and satisfaction for oneself," a sub-region of self-esteem. The results of the study suggest that physical activity programs are also effective in mental health, a psychological area, for the successful aging and self-esteem of female senior citizens in rural areas. The study of the elderly women in rural areas desperately needs a socio-cultural approach to address the impact of traditional values and a feminist perspective.
\end{abstract}

Keywords: Female Elderly, Rural Area, Self-esteem, Succesful Life, Physical Activity Program

\section{Introduction}

Human life expectancy has been steadily increasing in recent years. As a result, an aging society is rapidly progressing around the world. National improvements are needed to improve social, political and economic problems caused by an increase in the elderly population[1].

According to a recent report on life expectancy analyzed by the World Health Organization (WHO) and 35 (OECD) member countries, Korean women's life expectancy is 90.8 years in 2030, which is expected to lead to the fastest aging population compared to other countries. As the age increases due to the aging society, many elderly people say that physical activity and exercise are important to improve the health care and quality of life of elderly people with one or more chronic diseases[2]. Lack of

Received: June 22, 2021; $1^{\text {st }}$ Review Result: August 06, 2021; $2^{\text {nd }}$ Review Result: September 24, 2021 Accepted: October 31, 2021 
physical activity and exercise is causing diabetes, cardiovascular disease and cancer. It is reported that improving physical activity in older people can improve high blood pressure, diabetes, cholesterol, obesity, prevent cardiovascular diseases, improve health fitness such as muscular endurance and flexibility, and delay aging phenomenon[3][4].

As aging progresses, physical and cognitive functions gradually decline, especially in older adults, resulting in memory and learning impairments and cognitive impairments in the brain, difficulties in daily life, limited performance, and independent life. Furthermore, the decline in cognitive function is now as known as increasing the risk of dementia among senile diseases, and the increase in the elderly is expected to continue to increase along with chronic diseases[5]. To improve this, regular and active physical activity and exercise will greatly help elderly people improve cognitive function and prevent dementia. Studies have been reported that when the elderly continuously participates in physical activities, it has a positive effect on their self-esteem and that they are satisfied with their lives[6][7].

Compared to other age groups, the super-aged have more vulnerable characteristics in areas such as mental and emotional health, dementia, and life satisfaction, such as physical health, functional ability, and depression. This can appear to be a problem that can lead to poor satisfaction in life or quality of life when one reaches old age. The problem of the super-aged elderly is one of the new social problems that has never existed before, and it can be said that the government and society need to pay attention to it. Accordingly, this study intends to provide practical implications from the perspective of welfare for the elderly by identifying the characteristics of the super-aged elderly.

The increase in the elderly population can be recognized as an increasing number of people entering old age from early adulthood to middle-aged adulthood, while the number of young people and adolescents has decreased and the population birth rate has decreased. The number of people in their old age is increasing as the existing population is gradually aging. This increase in the elderly population has increased the rate of dependency in the population structure and caused various social problems, increasing the elderly's interest in healthy and successful aging. The loss of economic abilities and roles, the loss of many losses, such as the death of spouses or close people, and the weakening of physical conditions and mental health will lead to increased demand for medical and welfare. Mediation for older people therefore needs social and national mediation outside the perspective of individuals or families [1]. The study of the elderly women in rural areas desperately needs a socio-cultural approach to address the impact of traditional values and a feminist perspective. This is because the influence of traditional values based on agricultural society is still greatly affected by the elderly women in rural areas in Korea, and there is a lack of self-reliance and individual awareness as women. However, one cannot deny traditional values or ignore one's life as a woman. Therefore, by examining how social and cultural factors affect the health of female elderly people in rural areas, and how their life cycle experiences as women are, and by looking at the meaning as a whole, health-related lifestyle can be examined.

The research questions are as follows:

(1) First, how is the physical activity program for elderly women in rural areas structured?

(2) Second, does the physical activity program of rural elderly women improve self-esteem?

\section{Theoretical Background}

\subsection{Psychological Characteristics and Female Eldery}

Female seniors have not only been tied to free-paying housework in capitalist economic structures and patriarchal societies, but also have no opportunity to participate in economic labor amid sociocultural conditions that emphasize their role as caregivers in life cycles.

Also, according to traditional values, most elderly women who have died with their spouses transfer their economic rights to their sons and depend on their children, who live alone due to nuclear 
familyization and changes in values. In other words, the support of the elderly in Korea has traditionally been largely dependent on their families or children. However, changes in nuclear families and values caused by industrialization and urbanization have raised the issue of the burden of support for the elderly. Until now, Korea has seen the elderly problem as a family problem according to the traditional values of familism and filial piety. Then, with the enactment of the Welfare Act for the Elderly in 1981, the government began to engage in elderly issues based on the principle of "first-home welfare." In an aging society, the elderly problem is no longer a matter of individuals or families, but a social problem. It is also reported that economic problems for older people are the biggest challenges in a rapidly changing society without active social stimulus or economic preparation for old age[8]. Moreover, the elderly women are more economically dependent than the elderly men, and the most serious problem for the elderly Korean women is economic poverty. Therefore, presenting data without gender distinction when discussing the poverty problem of the elderly conceals the fact that poverty is concentrated on women in most elderly people, so a systematic analysis of the social process that causes the problem is needed.

It can be seen that the psychological aspect of the elderly has a great influence on successful aging. In addition, it has been reported that it is related to psychological and mental functions such as satisfaction with life, depression, cognitive function, and self-effectiveness, social relations such as occupation, social support, and leisure time. When describing or judging successful aging, the relationship between quality of life or satisfaction with life becomes a fundamental factor and an important variable[9].

Physical changes such as physical illness and loss of living ability occur during aging, psychological changes such as memory loss and cognitive decline, loss and alienation due to bereavement are closely linked to depression in older people[10]. Depression in older people is characterized by lethargy and hopelessness. Studies also show that depression in older people is likely to occur when they have physical disabilities or sensory disorders caused by aging, and depression syndrome increases as age increases. In general, depression in older people is reported to rise as age increases[11]. Older people in their 70s had higher levels of depression than those in their 60s, and a study of older people aged 85 and older showed that depression increases with age[12].

\subsection{Elderly's Self-esteem}

Self-esteem is a subjective mind that believes that one is worthy of being loved, precious, and can get results from anything[13].

Negative self-esteem is said to have difficulty controlling oneself or defending oneself against others. In other words, low self-esteem is considered worthless and weak, resulting in self-denial, selfdepreciation, and passive lifestyle. Positive self-esteem is essential for humans to be happy and function as human beings. Positive self-esteem is one of the greatest Chancellors a human being can have, as high self-esteem leads his or her entire life while developing an enterprising and energetic life at the same time[14].

Older people should be supported to feel positive self-esteem. It is necessary to promote self-esteem and prevent it from becoming an important psychological problem in the development process of the elderly by making them feel positive and interested. The increase in the proportion of the elderly population has led to the use of day care centers, nursing homes, and the use of welfare centers and other elderly facilities daily or several times a week.

Successful aging is important to stay healthy in old age. In the early stages of successful aging, it is defined in several fields, including biology, psychology, and physical, cognitive, and emotional wellbeing[15]. Successful aging is attracting attention from the perspective of embracing diversity in older people, away from the fragmentary and negative view of aging. We define successful aging as successful aging, keeping disease and disease-related disability risks low, cognitive and physical functions high, 
and active life participation as successful aging[16].

In addition to Rowe and Kahn[17], successful aging has a variety of theories, depending on the background of the times and the social context and the research perspective of scholars. Harvighurst[18] defined the elderly themselves as continuous life and satisfaction with their status and activities, as well as being satisfied and happy with their lives[19] as successful aging. Psychologist Ryff[20] sees successful aging as reachable in any course of life as a step in the development process and introduces a healthy state as successful aging, even if physical, without disease or disability[15]. Although the health of old age has declined, the high satisfaction of psychological and social health and life is defined as successful aging. Prior studies of successful aging have been recognized as a component of successful aging, but expectations for successful aging differ depending on the situation, experience and culture of each elderly person[16]. We find that the construction of successful aging works reciprocally in a variety of domains, such as physical health, psychological and social dimensions, rather than one specific factor[15]. In addition, it should not be overlooked that the meaning of the country's culture or environment may vary. For example, senior citizens in Korea value social relationships, family relationships, and interactions, but in foreign countries, individual goals or achievements, independence and autonomy are considered important factors of successful aging[21]. In addition, while satisfying economic preparation, stable life, respected life, and success of children are components of successful aging, productivity and volunteer work, self-realization, high level of cognitive function, and goal consciousness are emphasized in foreign countries. Combining the components of successful aging can be seen as a variety of factors, including physical health, psychological, social, cognitive functions, close family relationships, active participation in productive activities, and economic independence.

The majority of the elderly population is female and the proportion increases as they get older, highlighting the seriousness of the problem of elderly women[22]. In particular, Korea's rural areas are already an aging society, and young people leave to the cities due to developed industrialization, and only the elderly staying in rural areas, and most of them continue to work hard according to their life cycle experiences and socio-cultural characteristics. Therefore, it is important to study the individuality and uniqueness of elderly women in rural areas in order to understand the health and improve the quality of life.

\subsection{Successful Aging}

Physical health in old age has declined, but the high satisfaction of psychological and social health and life is a successful aging. The integrated model of Ryff[20] has criticized the study of successful aging, presenting a new model combining clinical theories dealing with global development, personal growth, and psychological domains of mental health[21].

Ryff can be said to have determined the impact of successful aging on older people by measuring the cyclical aspects of life by looking at who they are now and in the past, and their current and future lives. Furthermore, psychological well-being is derived from the concept of successful aging, and positive attitudes toward one's past life and life are important by embracing various aspects of oneself[22].

Based on criticism of existing research, Ryff emphasized the multi-dimensional nature of successful aging concepts in integrated models. We describe successful aging in four ways: self-acceptance as a factor in successful aging, positive relationships with others, mastery of autonomy and environment, and personal growth[23].

The SOC model of Baltes and Baltes presented the existing successful aging strategies as either selective and compelling to fill in areas where the existing concept of coping does not reflect individual importance and flexible development[24]. In addition, old age presented length of life, biological health and mental health, cognitive efficacy, social competence and productivity, personal control and life satisfaction[25]. This is evaluated that the SOC model in Baltes and Baltes can achieve its goal by 
selecting appropriate activities and developing and supplementing based on the ability to remain while acknowledging loss due to aging without looking at successful aging from a deterministic perspective[25].

Unlike separating criteria for successful aging into the presence or absence of disease, Rowe and Kahn[17] states that there may be risk potentials without the current disease, and that identifying the presence of disease is different from universal aging and successful aging[26]. A component of successful aging is that each of them is diversely combined and interrelated[27]. That is, physical and mental functionality can be maintained without disease and disability, and physical and mental functionality can actively participate in life participation, including productive activities. Continuing to maintain close relationships with others through active participation in life in various forms can bring meaning and vitality to life. This also emphasizes productive activities in successful aging.

\subsection{Health and Social Activities of the Elderly}

In prior research on the health and social activities of the elderly, health problems and alienation are identified as negatively recognizing the subjective health conditions of the elderly and lowering the quality of life[27][28]. The measure of successful aging in older people's health conditions is due to the correlation of psychological well-being or day-to-day function as an influence[29].

How older people perceive their health is very closely related to social activities[30]. It is subjective health conditions that indication. How one perceives one's health. In other words, subjective health refers to health conditions that cannot be measured in objective ways through evaluation of physical, psychological, and social aspects of one's health[31]. That is, subjective health conditions are continuous, subjective, and include psychosocial factors. This is said to be an important variable in predicting the psychological well-being and satisfaction of the elderly and the possibility of health and social activities[32].

The productive activities of the elderly are based on economic and social activities, excluding those of the home, and showed a mutually static correlation[32]. In addition, a study by Yang[33] found that about $55.4 \%$ of the elderly are inactive, and that despite the low social participation rate, they had a positive impact on the subjective quality of life and appeared as social activities as a subjective quality of life.

Other studies have shown that older women who continue to work in their old age are much more satisfied with their lives than older women who does not work[33]. This means that older people's productive activities have psychological effects depending on the type. It is said that participation in domestic activities and support activities for neighbors and friends reduced the sense of solitude among the elderly and that child support activities gave high happiness to the elderly women[34]. In general, the productive activities of older people centered on economic activities are positively correlated with successful aging, including satisfaction with life[35]. Studies on productive activities and successful aging have shown static correlation in social participation activities and social relations activities, and paid activities, attending welfare centers or senior college, and hobbies are shown as variables of successful aging[34]. In rural areas, agricultural work and involuntary activities of economic needs should be distinguished from productive activities[35]. This reported that the higher the frequency of participation in leisure and productive activities, the higher the psychological well-being, and it is necessary to revitalize leisure activities for the elderly in rural areas. As such, social activities such as economic activities of the elderly, community activities, volunteer activities, and religious activities are factors that improve the quality of life. This will help the elderly lead a vibrant and healthy life in rural areas by encouraging them to participate in social and leisure activities in the community. 


\section{Methods}

\subsection{The Study Subjects}

A total of 20 elderly women participated in the physical activity program in this study. The age group consists of people in their $80 \mathrm{~s}$ and $90 \mathrm{~s}$, with an average age of 87.2 years. The elderly women met in advanced and filled out the questionnaire, expressing that they are worried about health problems and children's problems, lonely and bored. They are seniors who need to be promoted psychologically and physically. Ten experimental groups participated in this physical activity program and ten control groups participated in the program are established.

\subsection{Research Tools}

\subsubsection{Self-esteem Scale}

Self-esteem measuring tools are developed by Rosenberg[36] by Jeon[37], and tools used by Lee[38] are used in this study. This measure consists of 10 questions (value, pride, ability, respect and satisfaction with oneself). It is a Likert-style five-point scale, and the questions corresponding to negative selfesteem are reversely calculated and then combined with those corresponding to positive self-esteem to yield the total score. The higher the score, the higher the level of self-esteem. Cronbach's a coefficient of self-esteem in this study =.It showed a confidence level of 725. Sub-regions of the self-esteem scale are as follows [Table 1].

[Table 1] Self-esteem Subarea

\begin{tabular}{ccccc}
\hline \multirow{2}{*}{ Self-esteem } & Sub section & Question Number & $\begin{array}{c}\text { Number of } \\
\text { Questions }\end{array}$ & Reliability \\
\cline { 2 - 5 } & $\begin{array}{c}\text { Pesitive self-esteem } \\
\text { self-esteem }\end{array}$ & $1,2,4,6,7$, & 5 & .776 \\
\hline & Total & $* 3, * 5, * 8, * 9, * 10$ & 5 & .652 \\
\hline
\end{tabular}

*Reverse questions

\subsection{Activity Program}

In the physical activity program, 10 subjects are organized into experimental groups, and a total of 10 sessions are conducted for 50 minutes each session. It consists of 10 minutes of greeting, 30 minutes of physical activity programs, and 10 minutes of feeling sharing and finishing. In the introduction part, Having a time to relax by saying hello with a song, and activities. In the development part, a physical activity program is carried out using media such as physical movements, music, pictures, and images. During the final stage, we introduced, shared, shared, and finished the program.

In order to ensure that the contents and composition of physical activity programs are appropriate and appropriate for each session, counseling-related experts (one professor and two doctors) are requested to review them. We looked at the overall flow and suitability of goals in the contents of the program and confirmed that the contents of goals for each session are evenly distributed. Since it is a program that is implemented for elderly women, it is also evaluated as suitable for the program using various media that can be carried out with interest and interest. The final draft of the physical activity program that is finally organized after this process is shown in [Table 2]. 
[Table 2] Physical Activity Programs

\begin{tabular}{|c|c|c|c|}
\hline Section & Session & Program & Contents(Activity) \\
\hline \multirow{2}{*}{$\begin{array}{l}\text { First } \\
\text { half }\end{array}$} & 1 & $\begin{array}{l}\text { self- } \\
\text { introduction } \\
\text { and making } \\
\text { nickname }\end{array}$ & $\begin{array}{l}\text { - Create and introduce self } \\
\quad-\text { Hopscotch } \\
\text { - Express with Body language following rhythm of who are you? song }\end{array}$ \\
\hline & 2 & $\begin{array}{l}\text { Finding self } \\
\text { young aged } \\
\quad \text { era }\end{array}$ & $\begin{array}{l}\text { - Hand activities } \\
\text { - Remind me of the 12th year animal and my birth day. } \\
\text { - Expressing my birth dream } \\
\text { - 'Express with body to the song "Happy Birthday" }\end{array}$ \\
\hline \multirow{6}{*}{$\begin{array}{l}\text { MIddle } \\
\text { part }\end{array}$} & 3 & $\begin{array}{l}\text { The most } \\
\text { precious body } \\
\text { in my life }\end{array}$ & $\begin{array}{c}\text { - Hand activities } \\
\text { - Making clay } \\
\text { - Making favorite color with playing Clay } \\
\text { - Printing hands on the clay } \\
\text { - Express your body to the song "Head, shoulders, knees, feet" }\end{array}$ \\
\hline & 4 & $\begin{array}{l}\text { My position } \\
\text { in my family }\end{array}$ & $\begin{array}{l}\text { - Hand activities } \\
\text { - Watching grandma's bowl } \\
\text { - Painting family in the fish pot } \\
\text { - Express your body to the song "Three Bears" }\end{array}$ \\
\hline & 5 & $\begin{array}{l}\text { Express and } \\
\text { Knowing } \\
\text { feeling }\end{array}$ & $\begin{array}{l}\text { - Hand activies } \\
\text { - Taking self feeling } \\
\text { - Making mirrors and look at the facial expression } \\
\text { - Express your body when you sing "My Face Like an Apple." }\end{array}$ \\
\hline & 6 & $\begin{array}{l}\text { Saying feeling } \\
\text { confidentially }\end{array}$ & $\begin{array}{c}\text { - Hand activities } \\
\text { - Designing masks } \\
\text { - Cover the masks and express } \\
\text { - Cover the masks and express feeling with musics }\end{array}$ \\
\hline & 7 & $\begin{array}{l}\text { Therapy in } \\
\text { my heart }\end{array}$ & $\begin{array}{c}\text { - Hand activities } \\
\text { - Express aching point of body } \\
\text { - Prescribing a cure } \\
\text { - Put it in a medicine bag and introduce it }\end{array}$ \\
\hline & 8 & $\begin{array}{l}\text { Fine } \\
\text { companion } \\
\text { plants }\end{array}$ & $\begin{array}{l}\text { - Hand activities } \\
\text { - Story of best friend } \\
\text { - Make a purifying plant } \\
\text { - Naming friends }\end{array}$ \\
\hline \multirow[t]{2}{*}{ Last part } & 9 & $\begin{array}{c}\text { Ejected } \\
\text { negative mind }\end{array}$ & $\begin{array}{c}\text { - Hand activities } \\
\text { - Sharing worry things } \\
\text { - Making flower fan } \\
\text { - Write down negative feelings on colored paper, tear and forget } \\
\text { - Throwing negative things }\end{array}$ \\
\hline & 10 & My wish & $\begin{array}{c}\text { - Hand activities } \\
\text { - Looking at self positively } \\
\text { - Designing wish Frames } \\
\text { - Writing wish }\end{array}$ \\
\hline
\end{tabular}

Examples of physical activity programs are shown in [Table 3].

[Table 3] Examples of Physical Activity Programs

\begin{tabular}{|c|c|c|c|}
\hline Program & My body with my life & Session & 3 \\
\hline Goal & $\begin{array}{l}\text { - Emotion mitigation and communication } \\
\text { enhancement } \\
\text { - Positive emotion and physical expression }\end{array}$ & ITModel & catharsis, projection model \\
\hline Preparation & \multicolumn{3}{|c|}{$\begin{array}{l}\text { Angel clay (white, seven colors), Astage, Sign Pen, } \\
\text { Head, shoulders, knees, feet. }\end{array}$} \\
\hline Activities & \multicolumn{3}{|c|}{$\begin{array}{l}\text { - Greeting each other } \\
\text { - fingers activities } \\
\text { - Express body to the song "Head, shoulders, knees, feet" } \\
\text { - Touching clay, developing hand strength and expressing positive emotions } \\
\text {-Experience the strength of both hands while rubbing clay. }\end{array}$} \\
\hline
\end{tabular}


-Looking at the palm and remind life

-Telling the life story

- Expressing gratitude to your precious body and hands

experience ownself as a precious person and a special being.

Please also indicate in your Activity Program Section that the Session 3 have a goal, preparation and activities that are shown in [Table 3].

\subsection{Data Collection Procedure}

This study conducted a physical activity program for elderly women in rural areas from March 17, 2021 to April 16, 2021. The required time was set to 50 minutes per session, and a total of 10 sessions were conducted, and 10 elderly women were selected. The place where this program is conducted is a lecture room of B Senior Welfare Center. The subjects of the experimental group moved desks and chairs to accommodate four to five people and placed them in three groups, and wore masks and social distancing are followed by the government's policy due to COVID-19.

The control groups are other program participants using the B Senior Welfare Center, who visited to play GO or taking. The program is conducted with one research assistant, and the program moderator played a role of researcher, guide, empathy, support and encouragement. The research assistant prepared the supplies, helped the subjects when they asked for help, and served to hold them next to them when using the supplies.

\subsection{Ethical Consideration of the Subject}

For ethical consideration of those participating in the study, prior to the commencement of the study, the purpose, procedure and outcome photography of the study were described and agreed in writing. The subjects were also informed that even if they agreed to participate in the study, they could terminate their participation anytime, and that the data collected will be treated with utmost confidentiality.

\subsection{Data Processing}

The data collected was analyzed using the IBM SPSS Statistic 20.0 program. Pre-examination of experimental and control groups was conducted with independent sample t-validation, and covariate analysis (ANOVA) with pre-score covariate was performed to identify the difference in mean between groups.

\section{Results and Interpretation}

The point of the research analyzing the effect of physical activity programs of female and elderly rural areas on self-esteem. The analysis results are as follows:

\subsection{Effects on Self-esteem}

\subsubsection{Self-esteem Pre-Homogeneity Test}

Independent sample t-verification was conducted to check whether the pre-score of female senior citizens in farming and fishing villages was homogeneous between the experimental group and the control group, and as a result, [Table 4]. 
[Table 4] Average and Standard Deviation of Pre-score for 'Self-esteem'

\begin{tabular}{cccccc}
\hline \hline \multirow{2}{*}{ Subfactors } & \multicolumn{2}{c}{ Experimental Group (N=10) } & \multicolumn{2}{c}{ Control Group (N=10) } & t \\
\cline { 2 - 5 } & $\mathrm{M}$ & $\mathrm{SD}$ & $\mathrm{M}$ & $\mathrm{SD}$ & .766 \\
\hline $\begin{array}{c}\text { Positive self-esteem } \\
\text { Negative } \\
\text { self-esteem }\end{array}$ & 16.30 & 3.20 & 15.20 & 3.22 & .232 \\
\hline Total & 14.60 & 2.91 & 14.30 & 2.87 & .371 \\
\hline
\end{tabular}

As shown in [Table 4], there was no statistically significant difference between the experimental group $(\mathrm{M}=21.70, \mathrm{SD}=4.83)$ and the control group $(\mathrm{M}=20.90, \mathrm{SD}=4.82)$ in the pre-inspection score for the entire self-esteem $(\mathrm{t}=) .371, \mathrm{p}>.05)$. Also, positive self-esteem $(\mathrm{t}=.766, \mathrm{p}>.05)$, a subfactor of selfesteem.05) and negative self-esteem $(\mathrm{t}=.232, \mathrm{p}>.05)$. The pre-inspection score in 05 also showed no statistically significant difference between the experimental group and the control group. Thus, we can see that the experimental group and the control group are homogeneous.

\subsubsection{Effect on Group Self-esteem}

To find out how the physical activity programs of rural female seniors have an effect on self-esteem, we compared the average and standard deviation scores of the results of pre- and post-examination and coordinated post-examination.

[Table 5] Meaning and Standard Deviation for 'Self-esteem' ( $\mathrm{N}=20)$

\begin{tabular}{|c|c|c|c|c|c|c|c|}
\hline \multirow{2}{*}{ Subfactor } & \multirow{2}{*}{ Group } & \multicolumn{2}{|c|}{ pre } & \multicolumn{2}{|c|}{ post } & \multicolumn{2}{|c|}{ Adjusted Post } \\
\hline & & M & SD & M & SD & M & SD \\
\hline \multirow{2}{*}{ Positive self-esteem } & experiment & 16.30 & 3.20 & 19.0 & 2.40 & 18.60 & .37 \\
\hline & control & 15.20 & 3.22 & 15.70 & 2.75 & 16.10 & .37 \\
\hline \multirow{2}{*}{$\begin{array}{c}\text { Negative } \\
\text { self-esteem }\end{array}$} & experiment & 14.60 & 2.91 & 11.20 & 1.69 & 11.09 & .63 \\
\hline & control & 14.30 & 2.87 & 15.50 & 3.72 & 15.61 & .63 \\
\hline \multirow{2}{*}{ Total } & experiment & 21.70 & 4.83 & 27.50 & 3.03 & 27.25 & .79 \\
\hline & control & 20.90 & 4.82 & 20.20 & 4.61 & 20.46 & .79 \\
\hline
\end{tabular}

To determine the self-esteem score between the experimental group and the control group, such as [Table 5], the results of covariate analysis for each group's pre- and post-examination are presented in [Table 6]. Covariate analysis for positive self-esteem, a subfactor of self-esteem, and covariate analysis for negative self-esteem are presented in [Table 7], [Table 8].

[Table 6] Covariance Analysis for 'Self-esteem as a whole'

\begin{tabular}{ccccc}
\hline \hline Random source & SS & df & MS & F \\
\hline Covariates (Pre-inspection) & 168.49 & 1 & 168.49 & $27.12^{* * *}$ \\
\hline Main Effects(Groups) & 228.96 & 1 & 228.96 & $36.85^{* * *}$ \\
\hline Residuals & 105.61 & 17 & 6.21 & \\
Total & 540.55 & 19 & &
\end{tabular}


As shown as [Table 6], post-inspection scores of experimental and control groups on self-esteem were shown to differ statistically significant between groups when the effects of pre-examination were eliminated $(\mathrm{F}=36.85, \mathrm{p}<.001)$ This means that physical activity programs for rural elderly women are effective in enhancing the self-esteem of elderly women.

[Table 7] Covariance Analysis of 'Positive Self-esteem'

\begin{tabular}{ccccc}
\hline \hline Random source & SS & df & MS & F \\
\hline Covariates (Pre-inspection) & 97.56 & 1 & 97.56 & $73.59^{* * *}$ \\
\hline Main Effects (Groups) & 30.33 & 1 & 30.33 & $22.88^{* * *}$ \\
\hline Residuals & 22.54 & 17 & 1.33 & \\
\hline Total & 174.55 & 19 & & \\
\hline$* * * \mathrm{p}<.001$ & & &
\end{tabular}

As shown as [Table 7], the post-test scores of experimental and control groups on positive self-esteem, a subfactor of self-esteem, were shown to differ statistically between groups when the effects of pretesting were eliminated $(\mathrm{F}=22.88, \mathrm{p}<.001)$ This means that physical activity programs for rural elderly women are effective in increasing the positive self-esteem of elderly women.

[Table 8] Covariance Analysis of 'Negative Self-esteem'

\begin{tabular}{ccccc}
\hline \hline Random source & SS & df & MS & F \\
\hline $\begin{array}{c}\text { Convarites } \\
\text { pre inspection }\end{array}$ & 82.31 & 1 & 82.31 & $20.64 * * *$ \\
\hline Main effencts (Groups) & 101.93 & 1 & 101.93 & $25.56^{* * *}$ \\
\hline Residuals & 67.79 & 17 & & \\
\hline Total & 242.55 & 19 & &
\end{tabular}

As shown as [Table 8], the post-test scores of experimental and control groups for negative selfesteem, a subfactor of self-esteem, were shown to differ statistically between groups when the effects of pre-testing were eliminated $(\mathrm{F}=25.56, \mathrm{p}<.001)$ This means that physical activity programs are effective in reducing the negative self-esteem of older women.

\subsection{Program Effects}

The programming session-specific composition of this study is divided into three main parts: early, mid and late. In the beginning, it was carried out to form Lapo like a natural meeting with the elderly, and in the middle and second half, physical activity programs were applied to promote the successful aging of the elderly. The physical activity program was carried out in the order of introduction, development, and completion.

In the introduction part, physical and emotional relaxation activities were carried out through greeting, asking for regards, and simple physical activities. In the development part, physical activity programs were conducted for each session, and conversations were recorded by voice during the process, and the results were recorded by taking pictures were recorded. In the final stage, the results were interacted, shared, and the feelings were shared after the activities were completed, ending with greetings.

The suitability of the content of the physical activity program in this study was verified by three experts (professor 1, doctoral course 2). In order to ensure that the program is appropriate for application 
to the subjects, the time and method of the inspection tool were examined through preliminary research, and the program was conducted twice for senior citizens of similar age.

The experimental group participating in the physical activity program for successful aging was found to be statistically significant in overall self-esteem than the control group. Looking at each sub-domain of self-esteem, the elderly who participated in the physical activity program improved their positive selfesteem and decreased their negative self-esteem.

This suggests that physical activity programs are positively effective in improving the self-esteem of older people. This study supported the study that the physical activity program for improving self-esteem for successful life of elderly women in rural areas makes them more satisfied with life, makes them healthy, and has a positive effect on their self-esteem[6][7].

When their self-esteem rises, the elderly actively cope with everything, do not become frustrated, and try to find positive factors. However, it suggests that the lower the self-esteem, the greater the feeling of loneliness and the greater the wounds caused by lack from outside[39].

\section{Conclusion and Suggestions}

Recently, most of the elderly population is female and the proportion is increasing as they get older. As a result, the seriousness of the problem of the elderly women is highlighted and the population of the elderly women in rural areas is constantly increasing, in this study, rural areas are already an aging society, and only the elderly remain in rural areas. In addition, due to the characteristics of rural areas, farming is forced to continue, and difficult farming is an important factor in the health care and successful aging of female and elderly rural areas. Therefore, research considering the individuality and uniqueness of elderly women in rural areas to understand the health and improve the quality of life has important significance. Positive self-esteem is essential for humans to function happily and positively, as most of their self-esteem is decreasing in old age due to physical and mental aging. Among the many ways to increase self-esteem, self-esteem is increased through respect and encouragement from others. Positive self-esteem is one of the greatest assets a person can have. Self-esteem leads a lifetime and leads an enterprising and energetic life. The positive self-esteem of the elderly is closely related to the physical and psychological domains, which are important in the development of the elderly.

This study is significant in that it developed a physical activity program for successful aging and had a positive effect on the self-esteem of elderly women. It is also meaningful in that it was targeted at elderly women in rural areas and broadened the age range. The suggestions of this study are as follows.

First, it is hoped that this will be applied as a preventive program for the elderly who participate in various programs while using the elderly welfare center. And I hope to be able to join the program for people over 65 and super seniors. It is hoped that various mental health prevention programs will proceed through physical activity programs for successful aging prior to aging.

Second, it is necessary to continuously implement a long-term physical activity program after analyzing the tendency in consideration of the individual characteristics of the elderly. The physical activity program used in this study was conducted for a short period of 10 sessions to confirm the improvement of self-esteem. Sustainable programs must be developed and implemented regularly to ensure effective improvement of each elderly person.

Third, it is necessary to develop various programs that can be applied not only to the media used in this study but also to future research.

\section{Reference}

[1] M. J. Hwang, Welfare of the aged and Community Care in an Aging Society, Journal of Public Society, (2020), Vol.10, 
No.2, pp.5-28, DOI: 10.21286/jps.2020.05.10.2.5

[2] G. R. Kim, N. H. Hwang, Policy Support for the Last Phase of Life for Oldest-Older People in a Post-Aged Korea, Korea Institute for Health and Social Affairs, (2016)

[3] H. G. Kim, H. K. Nam, G. S. Joe, The Effect of a Walking Program on Physical Health in Older Adults, The Journal of Muscle and Joint Health, (2008), Vol.15, No.2, pp.183-190, UCI: G704-SER000009893.2008.15.2.005

[4] H. J. Jang, E. J. Lee, Reproducing Rhythmic Idioms: A Comparison Between Healthy Older Adults and Older Adults With Mild Cognitive Impairment, Journal of Music and Human Behavior, (2019), Vol.16, No.1, pp.73-88, DOI: 10.21187/jmhb.2019.16.1.073

[5] M. S. Oh, H. S. Kim, Effects of an Integrated Activity Program on the Self-Efficacy and Depression of Underprivileged Elderly Women Living Alone, Journal of Korean Public Health Nursing, (2019), Vol.33, No.2, pp.258-269, DOI: 10.5932/JKPHN.2019.33.2.258

[6] K. B. Kim, J. Y. Park, The Effects of Physical Activity Participation on the Life Satisfaction and Sefl-Esteem of the Elderly, Journal of Sports Science Research, (2000), Vol.19, pp.3-19.

[7] S. I. Kim, H. O. Oh, The Effect of Aged Paritcipants' in Exercise Program of Leisure Flow Experience on Depression and Self-Esteem, Korea Sport Research, (2007), Vol.18, No.2, pp.259-270, UCI: G704-001366.2007.18.2.039

[8] B. E. Joe, Family Relations in Later Life : A Review and Prospect of Research During the Past 15 Years, Journal of Families and Better Life, (2007), Vol.25, No.1, pp.59-75, UCI: G704-000320.2007.25.1.005

[9] S. H. An, W. S. An, C. M. Heo, Effect of Health-related risk perception and Self-Efficacy on Health Promotion Behavior of Elderly Physical Activity Participants, Journal of Sport and Leisure Studies, (2016), No.63, pp.585-597, DOI: 10.51979/KSSLS.2016.02.63.585

[10] S. H. Yoo, G. D. Seo, M. Y. Yoo, B. J. Lee, J. H. Lee, Mental Health Social Welfare Theory, Shinjeong Publishing, (2018)

[11] C. S. Oh, The Effects of the Elderly's Subjective Health Perceptions and Quality of Life on Their Depression and Suicide Ideation, The Korean Journal of Health Service Management, (2012), Vol.6, No.2, pp.179-191.

[12] J. E. Go, S. H. Lee, A Multilevel Modeling of Factors Affecting Depression among Older Korean Adults, Mental Health \& Social Work, (2012), Vol.40, No.1, pp.322-351, UCI: G704-000500.2012.40.1.006

[13] R. G. Simmons, M. Rosenberg, Functions of children's perceptions of the stratification system, American Sociological Review, (1971), Vol.36, No.2, pp.235-249, DOI: 10.2307/2094041

[14] H. G. Choi, A Study on the Effect of Mental Health on Quality of Life for the Aged - Focused on the Aged and SuperAged, Hansung University Graduate School, Ph.D dissertation, (2010)

[15] I. Kwang, Perceptions of Successful Aging and Preparations for the Later Life Among the Baby Boom Cohort, The Journal of the Korea Contents Association, (2016), Vol.16, No.9, pp.460-472, DOI: 10.5392/JKCA.2016.16.09.460

[16] Y. S. Lee, The Relationships Among Leisure Sports Participation and Activities of Daily Living and Depression for the Elderly, Korean Society for the Sociology of Sport, (2008), Vol.21, No.2, pp.343-364, DOI: 10.22173/jksss.2008.21.2.343

[17] J. W. Rowe, R. L. Kahn, Successful Aging 2.0: Conceptual Expansions for the 21st Century, The Journals of Gerontology: Series B, (2015), Vol.70, No.4, pp.593-596, DOI: https://doi.org/10.1093/geronb/gbv025

[18] R. J. Havighurst, Social Psychological Perspective on Aging, The Gerontologist, (1968), Vol.8, No.2, pp.67-71, DOI: https://doi.org/10.1093/geront/8.2.67

[19] C. S. Lee, Y. S. Jung, H. K. Kim, Further Suggestion and Critical Review of Rowe and Kahn's Model of Successful Aging, Journal of Wellness, (2013), Vol.8, No.4, pp.1-11, UCI: G704-SER000002143.2013.8.4.009

[20] C. D. Ryff, Happiness is everything, or is it? Explorations on the meaning of psychological well-being, Journal of Personality and Social Psychology, (1989), Vol.57, No.6, pp.1069-1081, DOI: https://doi.org/10.1037/00223514.57.6.1069 
[21] S. O. Kang, Analysis of the effects of productive activities of the elderly on successful aging: Focusing on the elderly participating in the Chungbuk elderly job project, Gongju University Graduate School, Ph.D dissertation, (2009)

[22] J. W. Ahn, Predictors of Successful Aging in Community-dwelling Elders and Mediation Effect of Transcendence, The Journal of the Korea Contents Association, (2016), Vol.16, No.4, pp.582-593, DOI: 10.5392/JKCA.2016.16.04.582

[23] U. M. Kang, J. H. Kim, The Longitudinal Relationship between Employment Status Shift, Mental Health and Life Satisfaction among Baby Boomers, Korean Journal of Family Welfare, (2017), Vol.22, No.3, pp.379-400, DOI: 10.13049/kfwa.2017.22.3.1

[24] P. B. Baltes, M. M. Baltes, Psychological perspectives on successful aging: The model of selective optimization with compensation, Successful Aging: Perspectives from the behavioral sciences, Cambridge University Press, (1990)

[25] J. A. Kang, A Meta Analysis on Variables Related to the Korean Elderly' Successful Aging, Kyungpook National University Graduate School, Ph.D dissertation, (2015)

[26] J. J. Kim, A Study on Influential Factors forSuccessful Aging, Baekseok University Graduate School, Ph.D dissertation, (2008)

[27] J. H. Noh, Successful aging model of rural elderly women, Ewha Women University Graduate School, Ph.D dissertation, (2014)

[28] B. T. Ji, S. J. Seok, D. M. Sin, J. H. Jung, J. W. Kim, Analysis on the Effects of Health Exercise by Lifestyle Patterns of the Elderly, Korean journal of health education and promotion, (2010), Vol.27, No.2, pp.69-78.

[29] H. J. Woon, Study on the Influential Factors andPerception of Successful Aging, Kangwon National University Graduate School, Ph.D dissertation, (2010)

[30] S. H. Ahn, W. S. Ahn, C. M. Huh, Effect of Health-related risk perception and Self-Efficacy on Health Promotion Behavior of Elderly Physical Activity Participants, Journal of Sport and Leisure Studies, (2016), No.63, pp.585-597, DOI: 10.51979/KSSLS.2016.02.63.585

[31] Y. H. Oh, H. O. Bae, Y. S. Kim, A Study on Physical and Mental Function Affecting Self-perceived Health of Older Persons in Korea, Journal of the Korea Gerontological Society, (2006), Vol.26, No.3, pp.461-476, UCI: G704000573.2006.26.3.012

[32] J. H. Yeom, A Comparison Study of Self-Rated Health(SRH) Trajectory between Urban and Rural Older Adults: Using Latent Growth Modeling, The Journal of Rural Society, (2013), Vol.23, No.1, pp.193-239, UCI: G704000099.2013.23.1.009

[33] M. H. Yang, The relationship between social activities participation and subjective quality of lifeamong elderly, Ewha Womans University Graduate School, Master's thesis, (2009)

[34] S. D. Yoon, K. H. Han, Productive Activities and Psychological Well-being of the Rural Elderly in Korea, Journal of the Korea Gerontological Society, (2004), Vol.24, No.2, pp.57-77, UCI: G704-000573.2004.24.2.002

[35] J. C. Ahn, W. K. Lim, Effects of the Social Activity and Leisure Activity of the Rural Elderly on the Subjective Quality of Life, Journal of the Korea Contents Association, (2014), Vol.14, No.4, pp.189-210, DOI: 10.5392/JKCA.2014.14.04.189

[36] M. Rosenberg, Society and the Adolescent Self-Image, Princeton University Press, (1965)

[37] B. J. Jeon, Self-Esteem:a test of its Measurability, Yonsei Nonchong, (1974), Vol.11, No.1, pp.107-130.

[38] Y. H. Lee, Relations between attributional style, life events, event attribution, hopelessness and depression, Seoul National University Graduate School, Ph.D dissertation, (1993)

[39] A. R. Kim, O. H. Chae, Quality of Life for Elderly, Journal of Family Resource Management and Policy Review, (2001), Vol.5, No.1, pp.49-60. 